\title{
Ethical issues in dementia
}

\author{
Alistair Burns and John Harris
}

Public debate on dementia has intensified recently with scientific advances being scrutinised in the media, the genetics of Alzheimer's disease regularly portrayed as inextricably linked with the personal agony of whether to have 'the test' (which exists only for a small number of people) and the announcement by ex US President Ronald Reagan that he suffers from the disease. Several different areas provoke interest and speculation and this brief article attempts to highlight some, based on a recent meeting on the subject.

\section{Consent to treatment}

Foremost in some minds is the issue of consent. Consent guards the individual against unjustified interventions (even when others may be regarded as being better equipped to make such decisions) and has been defined by Raanon Gillon as "a voluntary un-coerced decision, made by a sufficiently competent and autonomous person, on the basis of adequate information and deliberation to accept rather than to reject some course of action that will affect him or her". Competence depends on the decision to be made. Further, determining competence for any particular decision is imprecise - who does the determination and how? It is considered an ongoing process and the difference in tacit and expressed consent is only one of expression. Consent is required to authorise touching of part of the body and in the absence of such one is liable to a charge of battery, irrespective of the nature of the physical contact.

Proxy consent has no legal validity (except in the case of minors), obtaining written consent is no guarantee of protection and acting in good faith is no defence. The law assumes that mental capacity is intact and the degree of the complexity of the task is important: the person may be deemed capable of agreeing to marriage vows but incapable of understanding the complexity of the disposal of their estate. There is a legal limbo as far as incompetent patients are concerned - the only two Acts of relevance to consent being the Mental Health Act (only for detained patients) and the National Assistance Act allowing for removal of individuals who are a danger to themselves or others. The best interests test (the $F$ test) can be invoked and is of particular importance in relation to the case of Tony Bland whose condition prompted the recent House of Lords' ethics enquiry. The duty of care cannot be ignored. Failure to act in a given set of circumstances may also leave one liable to legal action.

Three types of consent may pertain when mental capacity is impaired: hypothetical consent is where one is morally entitled to do something to and for someone if you can say that they would have consented, this is governed by the notion of what is reasonable by accepted standards; praxy consent is where another individual is empowered to consent on behalf of the person; advanced/prospective consent (the living Will) which is particularly important in the context of palliative care.

Areas of practical importance include the prescription of tacrine (THA), flu injections and screening procedures in dementia, and the ethics of medical practice codified in autonomy, beneficence, non-maleficence and equity. Some of these issues of consent may be helped by new jurisdiction of a personal manager acting in the best interest of the patient, taking into account all aspects of their care. Consent must be true consent or not at all and the best interest aspect may be more appropriate in cases of dementia. It may be that by raising the threshold of competence (to include not only an understanding of the action but of its implications) and restoring Wardship jurisdiction with personal managers to act as Guardians may be a way forward. The situation when "not to treat" is another matter based on the common law's adherence to acts and omissions. Legally, there is little difficulty with not treating pneumonia in a patient with advanced dementia but the issue of withdrawing treatment is problematic. Consent is only consent if truly informed and one cannot really make this case in dementia (hence 'best interest' may be the next realistic development). Different types of surrogate consent are being evolved but safeguards in the form of advocacy should be considered. The public's awareness of these issues is heightening as is their knowledge, interest and expectations in entering the debate. Euthanasia is highlighted, as always, as a quagmire involving the recent House of Lords' ruling in the Tony Bland case where the question of involuntary euthanasia being tolerated was raised.

\section{Driving}

The ethics of driving and dementia are something often encountered in everyday practice. 
Prescribed, relevant and prospective disability should be declared to the Driver and Vehicle Licensing Centre (DVLC). Elderly people drtve mainly to visit friends, to go shopping, to go to church and they tend to be more cautious, avoid long trips and motorways, drive more slowly and use other forms of transport. Patients with early dementia can retain a driving licence if there is adequate protection of insight and judgement but an annual review is required.

Young males are at the highest risk of accidents, the odds being similar to patients in the fourth year of progresstve cognitive decline. Most drivers are prepared to take advice to stop driving and a decision by patients themselves being the most compelling reason to stop. Advice from the family and the DVLC is least persuastve. If we are empowered to (or indeed have a duty to) stop patients with cognittve impairment from driving. are we discriminating against them if we allow young males who have a similar accident rate to go ahead.

\section{Presymptomatic screening}

Experience with Huntington's disease can provide a template on which to base experience for presymptomatic screening for Alzheimer's disease, although the two disorders are genetically very different. Apart from the small number of families who possess the genetic mutation for familial Alzheimer's disease, no test is yet available (Lovestone \& Harper, 1994). The presence of apolipoprotein E4 confers considerable risk but is not a diagnostic test. In relation to Huntington's disease questions include, will it do any harm, do we have a right to know, who should take part in the decision, should we test children and, most pressingly. should we test those at $25 \%$ risk? (this last situation refers to children of a person at $\mathbf{5 0 \%}$ risk - if a parent does not wish to know his/her status but if their child is tested the state of the parent can be easily and logically inferred). About $10 \%$ of the Huntington's disease population at risk have had a genetic test, and there is no reason to refuse the test in those individuals who ask. No suicides have been reported as a direct result of test results, although family upheaval does occur.

\section{Euthanasia}

With regard to euthanasia, the duty of a doctor is not necessarily to prolong life but is always to relieve suffering even in a patient with terminal decline. One has to establish whether the treatment is feasible (by predicting the likely outcome of the intervention), or desirable (does the treatment enhance quality of life). This involves the condition of life (which medical treatment may improve) and the meaning or value of a life (which medical treatment can never improve). The effects of intervention/non-inter- vention on the lives of patients and others must be considered, e.g. in the case in the treatment of urinary tract infections, the development of resistant strains can sometimes lead to potentially more serious problems in other people in the ward or hospital unit. The debate is about what constitutes a medical intervention (e.g. is food a medical intervention when given by a medical means such as a tube or syringe). This argument has only partly been resolved by the case of Tony Bland, however, his ruling is particularly important because it effectively legalised involuntary euthanasia by assuming that Mr Bland had no interests (or even had an interest to die in the absence of a directive from him). The issue of cost of care was never raised.

One way of avoiding the problem of deciding whether something is a medical intervention or not would be to address the question: what legitimate moral claim does the patient have on the community? If the patient's claim to have his or her suffering relieved by a life terminating decision or by withholding or withdrawing treatment is one which should be sustained, then it does not matter very much whether the means of meeting this legitimate claim can be fairly described as medical or not. This was largely the decision arrived at by the Law Lords in the Bland case. It is the issue of the patient's legitimate interests that concerns about euthanasia must address and not the narrow definition of whether or not the intervention is medical.

\section{Acknowledgements}

This annotation was prompted by a conference on Ethical Issues in Dementia held in Manchester on 8 November 1994. Other speakers at the conference were: Margaret Brazier, Professor of Philosophy, University of Manchester; Dr Calliope Farsides, Lecturer in Philosophy, University of Keele; Dr Rob Jones, Senior Lecturer in Old Age Psychiatry, University of Nottingham; Dr Sean Lennon, Consultant Old Age Psychiatrist, Withington Hospital, Manchester; Mike Horan, Professor of Geriatric Medicine, Withington Hospital, Manchester; and Dr David Craufurd, Senior Lecturer in Psychiatric Genetics, University of Manchester.

\section{Reference}

LOVESTONE, S. \& HARPER, P. (1994) A genetic test for Alvheimer's disease? Psychiatric Bulletin, 8, 645.

*Alistair Burns, Professor of Old Age Psychiatry. University of Manchester, Withington Hospital, West Didsbury, Manchester M20 8LR; and John Harris, Professor of Applied Philosophy, University of Manchester

*Correspondence 